
\title{
IN SEARCH OF MEANING ABOUT DIGITAL TEACHING AND
LEARNING: A COLLECTIVE REFLECTIONS
}

(D) Yazilmiwati
Yaacob $^{1}$
(D) Malissa Maria
Mahmud $^{2}$
(D) Nur Izzati
Mustamam $^{3}$
(D) Rozaini Ahmad
(D) Noor Syazwani
Ishak
(D) Md Sairolazmi
Saparman
(D) Muhamad Safwan
Mohd A'Seri
(D) Mohamed
Nadzri Mohamed
Sharif

${ }^{\prime}$ General Studies Department (GSD), Sunway College, Malaysia. 'Email:yazilmiwati@sunway.edu.my

${ }^{2}$ Centre for English Language (CELS), Sunway University, Malaysia. •Email:malissam@sunway.edu.my

${ }_{3,4,5,5,7,8}$ General Studies Department (GSD), Sunway College, Malaysia.

${ }^{s}$ Email:nurizzatim@sunway.edu.my

"Email: rozainia@sunway.edu.my Tel: +603-74918622

${ }^{5}$ Email:syazwanii@sunway.edu.my

${ }^{6}$ Email:sairolazmis@sunwav.edu.my

'Email:safwana@sunway.edu.my

${ }^{8}$ Email: nadzris@sunway.edu.my

\section{ABSTRACT}

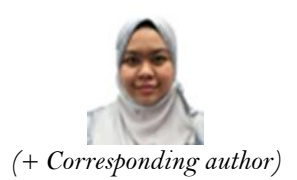

(+ Corresponding author)
Article History

Received: 5 July 2021

Revised: 9 August 2021

Accepted: 13 September 2021

Published: 29 September 2021

\section{Keywords}

Teaching

Learning

Technology

E-Learn

COVID-19

Collective reflection.
The Covid-19 pandemic has affected various sectors particularly the education sector. The decision by the Malaysian government to close down higher learning institutes and schools has forced educators and teachers to switch their teaching and learning techniques from face-to-face to completely online. This situation has pushed the lecturers from the General Studies Department, Sunway University, Malaysia to master not only the technological tools, but also the pedagogic aspect that drive the entire process, to ensure the teaching and learning process can be carried out properly. Within a short period of time, different methods and modalities were designed and experimented, yet little is known on how such abrupt and rapid modifications affect the overall quality. Considering the value of experiences and reflections, this study probes on the mediated experiences of GSD academics on online teaching and learning, whereby a qualitative-research design was leveraged in a plethora of collective reflections in using E-Learn. The findings revealed that E-Learn has a huge potential to be effectively employed for synchronous and asynchronous modalities due to its userfriendly features and tools within the capacity to disseminate information, structure virtual lessons, record students' involvement, monitor reports and deploy both formative and summative assessments. This study concluded that the various features of E-Learn had tremendously assisted the GSD lecturers during the online teaching and learning process, and is deemed suitable be used as a platform or Learning Management System (LMS) for online teaching and learning activities.

Contribution/ Originality: This study documents the mediated experiences of GSD academics to research on the current circumstance whereby a qualitative-research design was leveraged. The findings revealed that E-Learn have a huge potential to be effectively employed for synchronous and asynchronous modalities due to its userfriendly features and tools. 


\section{INTRODUCTION}

The closing of higher learning institutes and schools due to Covid-19 pandemic has affected the structure of teaching and learning in which the traditional face-to-face is substituted with online teaching. The Malaysian National Security Council (MNSC), after the Special Malaysia Cabinet Meeting on the execution of Movement Control Order (MCO) on $16^{\text {th }}$ of May 2020, approved the suggestions by the Ministry of Higher Education (MoHE) on the handling of academic activities that involved higher learning institutes' campuses during and post-MCO. According to MoHE in the media statement on $27^{\text {th }}$ of May 2020, all teaching and learning activities must be done online until $31^{\text {st }}$ of December 2020 (Palansamy, 2020). All face-to-face teaching and learning activities were prohibited with some exception for several group of students who were required to return to their campuses to undergo regular teaching and learning classes while adhering to strict Standard Operating Procedure (SOP). The online teaching and learning method have forced educators to familiarize themselves with numerous online tools to ensure that teaching and learning continues under the new norm. Many have resorted to using various applications and digital platforms to conduct online classes during the MCO, such as WhatsApp, Google Classroom, Zoom, WebEx, YouTube and many others.

Numerous researches have established that the employment of technological integration in the context of teaching and learning is tremendously beneficial in which it offers both opportunity and challenges for pedagogical reforms. Institutions, teachers and students are the encompassing stakeholders wherein their perceptions, attitudes, and experiences are broadly measured to understand the success or failure of the introduced technology. At this juncture, stakeholders' perspectives involved are goldmine in order to move forward for the reason that experiences evidently shape the beliefs and values (Hicks, Lee, Berson, Bolick, \& Diem, 2014). For instance, the Technological Pedagogical Content Knowledge (TPACK) framework developed by Koehler and Mishra (2009) has been utilized as an analytical tool to understand the range of knowledge and skills required in the purposeful incorporation of technology into teaching and learning. To probe further into the teacher's varied level of aptitude, a model was designed (Wang et al., 2020), and external limitations have been found to impact the teachers' technological usage (Ertmer, 2005; Ertmer \& Ottenbreit-Leftwich, 2010).

The E-Learn platform used by the lecturers in Sunway Education Group has its own benefits and unique features. One of the main features of E-Learn is the 'Announcement', which is used to relay important information to the students, such as grouping updates, venue changes and class activities. Besides that, there are also 'Template Assessments' that helps lecturers to design online assessments. There are various forms of templates that can be found such as 'Multiple Choice Questions (MCQ), True or False, Fill-in-the-Blank, Short Essay, and Report'. Furthermore, monitoring students' progress and scores through the 'Grade Centre' feature can be done effortlessly. All assessments; summative or formative are submitted through E-Learn, and is automatically compiled in 'Grade Centre'. Another feature that can be found in E-Learn is the 'BB Collaborate' which is used to support synchronous and asynchronous communication. Lecturers and students can use either the video or audio feature; for example, students can write any comment using the chat tool available in 'BB Collaborate' to ask questions, give feedback or share comments. These features have helped the lecturers to conduct their online classes and simultaneously use it as a Learning Management System (LMS). According to Mahmud and Bakar (2021), the students were satisfied with the use of E-Learn as part of their learning because it affords flexibility and better engagement. Hence, the purpose of this study is to examine the experiences of GSD academics on the usage of E-Learn as the teaching and learning modality whereby a qualitative-research design was leveraged to probe on the plethora of collective reflections and experiences.

\section{METHODOLOGY}

Reflective writing research method has become reputable as an important component of reflective practice, and fundamental to the concept of learning from experience (Colomer, Serra, \& Canabate, 2020). It has been asserted 
that reflective writing research method augments unique connections between incongruent sets of information, and eventually contribute to new standpoints on issues (Chan, Wong, \& Luo, 2021; Hannah \& Jiahui, 2020). Numerous means can be employed to juxtapose reflective writing. For this study, the reflections of the researched phenomena were of the researchers themselves, which is the data, involving the writer interacting with and interpreting the data and recording their analytical processes.

This method is used to capture the lecturers' and researchers' own experiences in using E-Learn Blackboard as the medium for online teaching and learning process. Reflective writing method is ubiquitous, specifically in assessing reflective practices within the tertiary education setting (Griffin, Lorenz, \& Mitchell, 2010; Ryan \& Ryan, 2013). Jennifer (2004) noted that reflection in experiential education is acknowledged as a valued instrument. In this context, the data obtained can be used to reengineer programs and curriculum offered, executed through the metadata and mechanism of the university. The process of reflecting or writing on one's own experience after doing any job, practice or using tools in doing their work is called the Reflective Practice Method. According to Jasper (2005), the data obtained through reflective writing will be analyzed to answer the research question. This method is quite similar to the content analysis technique because of its elective and holistic natures. Taking that into account, reflective writing technique was used in this research where the researchers share their experience is using that features that can be found on E-Learn as the main platform in the online teaching and learning process for General Studies subjects' classes.

Within the General Studies Department, there are 15 academic staff that consisted of 10 full-time staff members and 5 part-time staff. The subjects that are being taught by the General Studies Department lecturers are the Islamic and Asian Civilization (TITAS), Ethnic Relations, Malaysian Studies 1, 2 and 3, Malay Language Communication 1 and 2, National Language A, Moral Education, Islamic Studies and Community Services. All of these subjects are compulsory subjects as determined by the Malaysian Qualification Agency (MQA) for all students of public and private higher learning institutes. All lecturers in the General Studies Department use E-Learn as their Learning Management System (LMS). There were 7 researchers involved in the study, and they shared their own experiences using the E-Learn. Each one of them has used E-Learn for online teaching and learning process for at least one year. These researchers took around one week to reflect and write about their experiences using the E-Learn after a year of familiarizing and mastering the E-Learn as a tool for teaching and learning process.

There were four important steps taken by the researchers while doing the reflective writing. First of all, the researchers had to choose one features from the E-Learn that they are most familiar with while carrying out the teaching and learning process. Secondly, they had to write the steps of how to use the chosen features from the ELearn. The third step was to list down all the benefits from the E-Learn. Last but not least, the researchers had to complete a guided reflective writing on the features of E-Learn that they have used and benefitted from. The researchers utilized question prompts to probe the experiential reflections from the involved lecturers. The question prompts comprised of the following:

1. Which are the most important features of E-Learn?

2. What are the steps for using the features?

3. What are the benefits from using the features?

The data obtained from the written reflections were reviewed and recorded, and consequently interpreted by employing (Hatton \& Smith, 1995) taxonomies, which governs the decorum of reflections.

\section{RESULTS AND DISCUSSIONS}

The following sub-sections $(3.1$ - 3.7) entails the (1) Descriptions of E-Learn Features and Corresponding Figures taken from the actual implementations in GSD, Sunway College, (2) Lecturers' Reflective Writing and (3) Discussions of Findings. 


\subsection{E-Learn Announcement}

The E-Learn Announcement is a platform used to connect the lecturers with their students. It is a channel of communication used by the lecturers to relay various kind of information about their respective classes. Besides that, the E-Learn Announcement feature also functions as a way to form assignment groups using online form. All announcements made through here will be received by the students through their emails. Figure 1 shows an example of E-Learn Announcement made by a lecturer for their student:

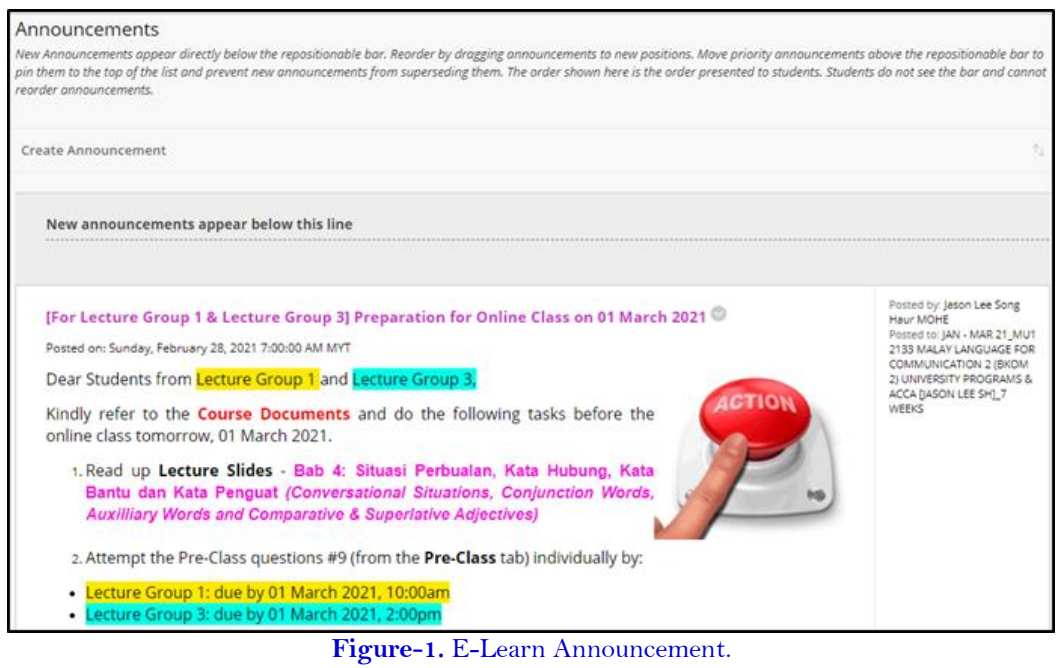

"For me, the benefit of this feature is mainly the announcement board. It allows me to make any announcement to the students. The announcement can be about instructions or guidelines for formative or summative assignments such as pre-class, in-group activities, pop quizzes, midterm tests or final examinations. Besides that, the announcement board is also used as communication network between my students and myself to fill in the information regarding group assignments through Microsoft Excel link that was prepared earlier. Furthermore, this platform is very important to get students' attention and focus in following the latest updates through instructions or guidelines, images, schedule or link that I provided".

The above statement is based on Lecturer 1 experience in which the feature of E-Learn announcement is beneficial several tools in the communication between lecturer and students in formality. In this context, such feature is able to support students' learning experience wherein all class activities including pre-classes and live classes are announced through E-Learn Assignment feature. Additionally, this feature also acts to inform the students about all information related to coursework and assignments including team training, quizzes, projects and final examinations. The E-Learn Assignment is also used to remind students of the classes that they have to attend wherein a link for the scheduled live classes are also posted. As stated by Iffat Rahmatullah (2021), the Announcement tool is employed by the instructors is deemed a useful feature to inform students about the classes. This is automatically done via the course Messages feature to communicate on the details of lectures and tutorials.

\subsection{Content Folder}

Content Folder is a file arrangement system available in E-Learn. The lecturers in General Studies Department follow a standard set by the department to help themselves and the students to fund information related to their subjects in E-Learn. In this section, the lecturers can arrange their pre-recorded classes and activities files, live class activities, unit assessments and marking system for the students. All the files that were created and arranged will help the lecturers the carry out the teaching and learning process and help the students to access the tasks given to them. The sample of Content Folder is shown in Figure 2 below: 


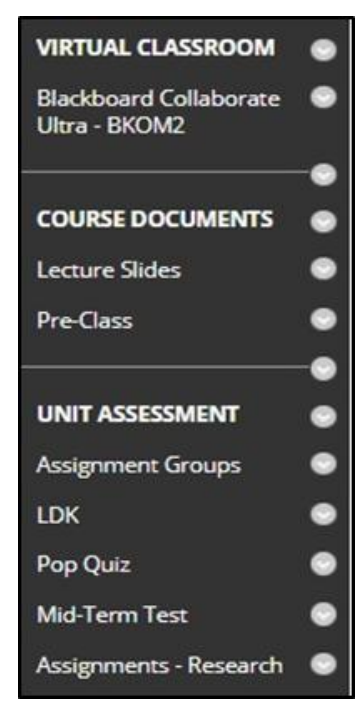

Figure-2. Content Folder.

"The main advantage of using the E-Learn Blackboard Content Folder is that it helps the lecturers to locate the correct locations for keeping teaching materials such as students' activity files, lecture notes files, rubric files, list of important dates for submission of students' assignments and many others. By using the Content Folder feature, I can arrange my E-Learn in an interesting and easy manner in order to help my students to make any references easier. On top of that, another benefit of the Content Folder is it allows lecturers to identify and control the access of any file for the students and lecturers have the authority to lock the file if necessary. In my opinion, the Content Folder feature is very useful by using E-Learn Blackboard as it allows lecturers to put important web or tool links that can be used by students".

The above statement is based on Lecturer 2 experience in which the feature of E-Learn Content Folder is tremendously beneficial for online content management. In this context, the files created are arranged in a manner that is organized to be easily accessible for students. As stated by Wang et al. (2020), lecturer or instructor can use this function to create, delete, copy, update and backup the contents of a course such as syllabus, course modules, topics, readings, slides and lecture videos, quizzes, surveys, tests, labs and rubrics. Compared to face-to-face approach, the Content Folder feature offers great advantages such as reusability, easy maintenance, low cost and automatic assessment.

\subsection{Live Class using BB Collaborate Ultra}

Blackboard Collaborate Ultra is a teaching platform used by the lecturers to go live with their students. This platform uses web conferencing tool which allows the lecturers to communicate, collaborate, interact and engage with their students live. Through this platform, lecturers usually have to create a class setting based on the topic that they are going to teach a day before the class and share the class link using E-Learn Announcement. Students can join the class using the link provided to them through emails. On top of that, live class that utilizes the Blackboard Collaborate can also be recorded and posted for students who are not able to attend the live class. This platform also allows the students to see their lecturers during live class and listen to the discussion shared by their lecturers. Students can also present their assignment live and 'Question E' Answer' session between students and lecturers can also be carried out. An example of a live class using the Blackboard Collaborate Ultra feature can be seen in Figure 3. 


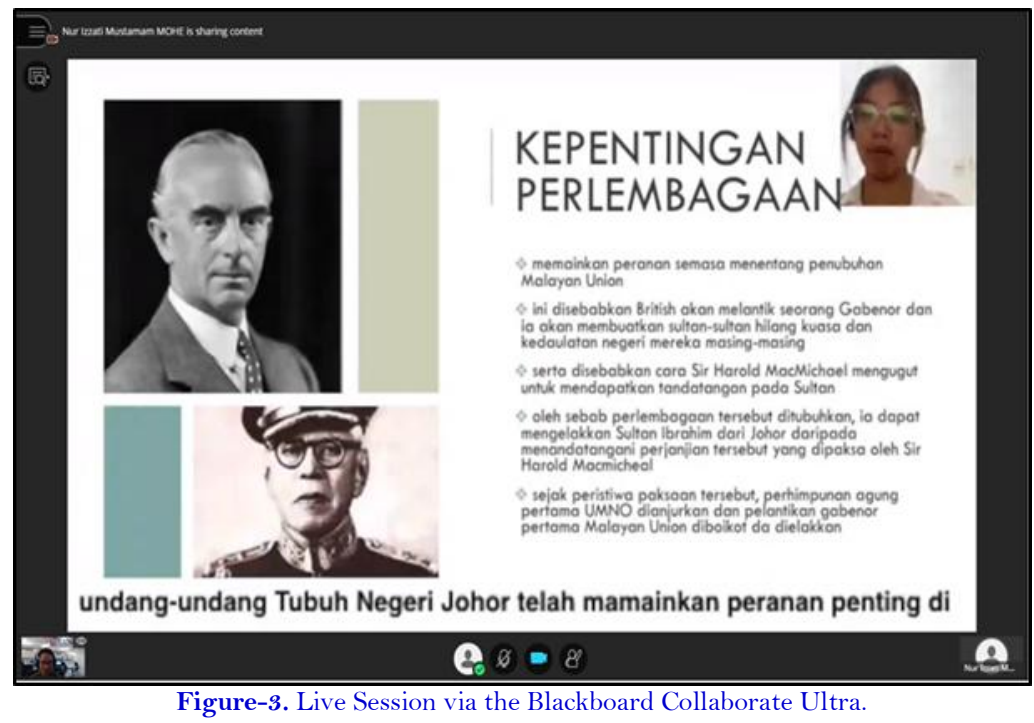

\begin{abstract}
"One of the advantages of doing live class using BB Collaborate is that I do not have to download a different software for my online classes because E-Learn already has such application where I can do my virtual classes which is called BB Collaborate Ultra. This application allows students to attend their classes virtually. Besides that, this is a very systematic application which a complete feature. Lecturers can share videos or PowerPoint presentations. For example, during my lectures, I usually put up the lecture slides and videos as learning materials for my students. In addition to that, by using BB Collaborate I can ensure there are 2-way communications between me and my students. Microphone, camera, and chat box are available within the application. Students can directly interact with their lecturers during learning sessions. For instance, when I am teaching a class, students can be seen responding through the chat box, asking questions, or sharing opinions and information. Furthermore, this application can also be used to record teaching materials. Students can easily access all recording of their classes in the recording segment for their references. This allows students who are not able to attend due to various reasons to be able to participate in the teaching and learning sessions".
\end{abstract}

The above statement is based on Lecturer 3 experience where the use of E-Learn BB Collaborate has facilitated the lecturers to implement the class directly. The facilities available on E-Learn BB Collaborate have supported the teaching staff in delivering the learning materials to students. In this context, the features available on the platform are found to be able to support different learning activities. For example, the built-in visual and audio have allowed for communication to take place between lecturers and students, and students with their peers. This finding is supported by Mahmud and Bakar (2021) who stated the in-built design and features on E-Learn enable prescribed self-regulations, making students to be more prepared and motivated, which simultaneously scaffold and stimulate interactions which can lead to better engagement. Another highlighted input was the availability of recording mechanism wherein asynchronous (live) sessions can be recorded for the students to watch the session again. This is an essential feature for the students who are not able to attend the scheduled session in which they can replay important parts according to their own pace. As recommended by Chen, Dobinson, and Kent (2020), a combination of recorded and unrecorded sessions is advisable to lessen online anxiety among students. As such, this E-Learn feature is immensely beneficial.

\title{
3.4. Monitoring of Students' Attendance
}

There are two ways lecturers can monitor their students' attendance. Firstly, by using Grade Center and during live class. In Grade Center, lecturers will make sure all pre-class activities are completed by the students. Students are provided with pre-recorded lectures and after that, they are required to complete pre-class activities. If students did not complete their pre-class activities, they will be considered as absent to that class. Students who did 
not complete their activities will be warned during live class. If they still did not complete their pre-class activities before the live class, their attendance will be marked as zero. Figure 4 below shows an example of Pre-Class Grade Center:

\begin{tabular}{|c|c|c|c|c|c|}
\hline GROUP & $\theta$ & $\begin{array}{l}\text { PRE-CLASS 1: } \\
\text { BAB 2- }\end{array}$ & $\begin{array}{l}\text { PRE-CLASS 2: } \\
\text { BAB 2. }\end{array}$ & $\begin{array}{l}\text { PRE-CLASS 1: } \\
\text { BAB } 3\end{array}$ & $\begin{array}{l}\text { PRE-CLASS } 2 \\
\text { BAB } 3\end{array}$ \\
\hline G1-NS - K 7 & & 6.00 & 10.00 & 10.00 & 10.00 \\
\hline G1.NS - K 7 & & 7.00 & 8.00 & 8.00 & 8.00 \\
\hline G1-NS - K 7 & & 9.00 & 10.00 & $(1$ & .. \\
\hline G1-NS.K 7 & & 4.00 & 1.00 & 9.00 & 6.00 \\
\hline G1-NS-K 7 & & 9.00 & 10.00 & 10.00 & 10.00 \\
\hline G1.NS-K 7 & & 9.00 & 9.00 & 10.00 & 7.00 \\
\hline G1. NS - K 7 & & 6.00 & 8.00 & 10.00 & 8.00 \\
\hline G1-NS.K 7 & & 10.00 & 10.00 & 10.00 & 8.00 \\
\hline G1-NS-K7 & & 10.00 & 10.00 & 10.00 & 9.00 \\
\hline G1-NS-K 7 & & 8.00 & 10.00 & 10.00 & 9.00 \\
\hline
\end{tabular}

Figure-4. Pre-Class Grade Center.

Aside from monitoring students' attendance through the Grade Center, lecturers can also do it during live classes. Using the students' attendance list from the live classes, lecturers can download the list in Excel format and convert it into I-Check In. After all the names in the list have been transferred into the I-Check In, lecturers can monitor their students' attendance using web attendance and consequently do the absenteeism report. These features are suitable for lecturers who share the E-Learn, teach many classes and large number of students. For example, the Islamic and Asian Civilization subject and Ethnic Relations subject for January to March 2021 semester has 5 to 6 class groups for one E-Learn course site. By using the attendance transfer to I-Check In method, lecturers can easily manage and monitor their student's attendance based on their classes and make sure no student got neglected. As shown in Figure 5 , students' attendance list who attended the live class can be seen:

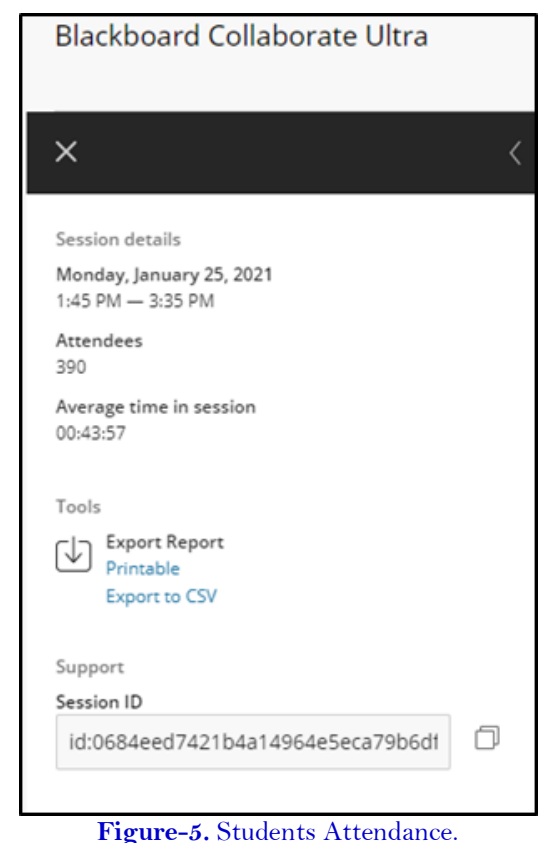

Figure-5. Students Attendance. 
"The benefit of monitoring students' attendance through E-Learn is that it allows me to record students' attendance for both pre-classes and live classes. Moreover, it also allows me to monitor students' involvement in all classes. For example, in a class of 150 students, I can easily record their attendance and involvement during the class using this technique. Large number of students will not be an issue for me to manage their attendance and involvements in my pre-classes or live classes".

The above statement is based on the experience of Lecturers 4, where the E-Learn feature has helped the lecturers monitor student attendance seamlessly. In this context, this feature can support lecturers for both preclass classes and live sessions attendance. According to Fearnly and Amora (2020), LMS enable the monitoring and tracking of students' scheduling, learning, testing, communication, and registration process. Despite the large class size, the Blackboard Learning Management System (LMS) can record all activities and student attendance automatically. In this context, the administrative task of making roll calls or calling for student's names which is synonymous with face to face classes is no longer necessarily. Moreover, attendance is almost always measured to knowledge retention and engagement (Nieuwoudt, 2020). The online presence is considerably imperative to the university administration whereby it is correlated with good performance (Elsamanoudy, Al Fayz, \& Hassanien, 2020).

\subsection{Smart View}

The Smart View function is used to find information about students' group activities in every class. After assignment groups have been formed, lecturers will key-in the names of every group member manually or use a self-enrollment method where the students are able to choose their own groups. After that, lecturers will monitor their students based on the groups, so nobody is left without any group. Figure 6 below shows an example of Smart View and amount of group members in each group and Figure 7 shows how lecturers monitor their students' assignments:

\begin{tabular}{|c|c|c|c|c|}
\hline$\gg$ & Bulk Actions & View Options & & \\
\hline$\square$ & NAME & & GROUP SET & ENROLLED MEMBERS \\
\hline$\square$ & G1-NS-K1 & & G1-NS-K & 13 \\
\hline$\square$ & G1-NS-K 10 & & G1-NS-K & 13 \\
\hline$\square$ & G1-NS - K 11 & & G1-NS - K & 13 \\
\hline$\square$ & G1-NS-K 12 & & G1-NS-K & 13 \\
\hline$\square$ & G1-NS - K 13 & & G1-NS-K & 13 \\
\hline$\square$ & G1-NS - K 14 & & G1-NS - K & 13 \\
\hline$\square$ & G1-NS-K 15 & & G1-NS - K & 13 \\
\hline$\square$ & G1-NS - K 16 & & G1-NS - K & 12 \\
\hline$\square$ & G1-NS-K 17 & & G1-NS-K & 13 \\
\hline$\square$ & G1-NS - K 18 & & G1-NS - K & 13 \\
\hline$\square$ & G1-NS - K 19 & & G1-NS - K & 13 \\
\hline$\square$ & G1-NS - K 2 & & G1-NS-K & 13 \\
\hline$\square$ & G1-NS - K 20 & & G1-NS-K & 13 \\
\hline$\square$ & G1-NS - K 21 & & G1-NS - K & 13 \\
\hline
\end{tabular}

Figure-6. Smart View 


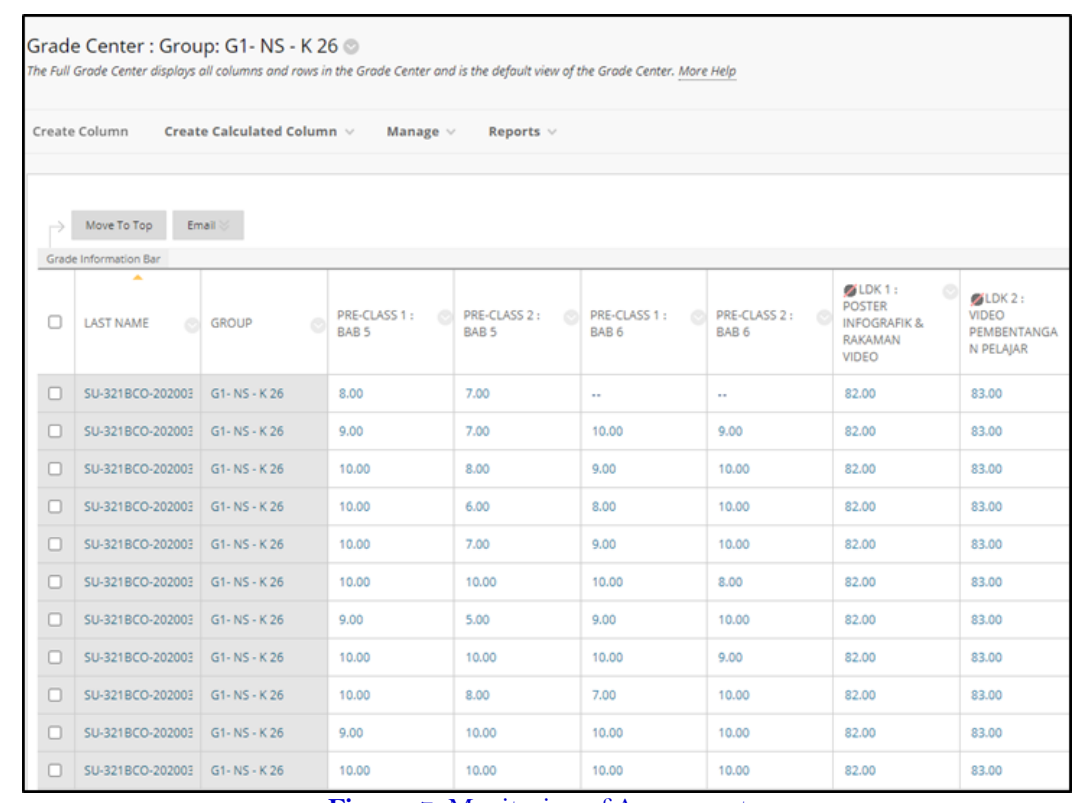

Figure-7. Monitoring of Assessments.

"Smart View plays a very integral part in my class that has a huge number of students and classes. For example, my Ethnic Relations subject has 6 different classes, and each class has around 30 to 45 groups. By using Smart View, I can still monitor the progress of my students within their own groups even though they share the same E-Learn system. Through Smart View, I can identify which groups have already submitted their assignment and which have not. Moreover, $l$ can also monitor which group members are actively participating in group activities. The (...) symbol in the figure above shows that the students have not submitted their assignment. By using the Smart View platform, lecturers can easily monitor and review their students' assignments and inform the students if they have not submitted their assignments within the time period provided. The Smart View feature has helped me to identify and check the progress of each group. For instance, with 35 groups of 456 students in my class, the checking of each member of each group will take a long time. By using Smart View, I can save time by looking up the list of students who registered into any particular group".

The above statement is based on the experience of Lecturers 5 using Smart View feature which is quick, simple, efficient, and timesaving. At this juncture, lecturers can view the progress of the following items; grouping, performance for a particular assessment, and status of attempts for an assessment assigned. This yielded input is found to corroborate with findings of Al Meajel and Sharadgah (2018) that the painstaking process of monitoring can be alleviated through the applications of available features. Furthermore, Smart View is able to scaffold nonperforming students. This is easily done by emailing the students directly via the Grade Center feature. With the information of non-performing students, lecturers not only are more alert of, but more importantly, remedial materials or alternative assessments can be created for them (Snellings, 2021).

\subsection{Marking System using Grade Center}

Students' Marking System using Grade Center has helped the lecturers in managing and checking their students' activities. Using Grade Center allows the lecturers to mark the score of their students using a rubric that has been included in the E-Learn system. This helps the lecturers to refer to the marking criteria for all class activities. Together with that, there are a few assessments that can be auto marked by the system such as quizzes, pop quizzes and final examinations. Lecturers can monitor all students' assessments using E-Learn and at the end of the semester, all marks will be uploaded to the exam template. The grade center system in E-Learn helps the lecturers to review all students' activities either summative or formative and it also helps the lecturers to handle big 
classes with large number of students. Example of grade center used by lecturers to monitor their students' assessments is illustrated in Figure 8.

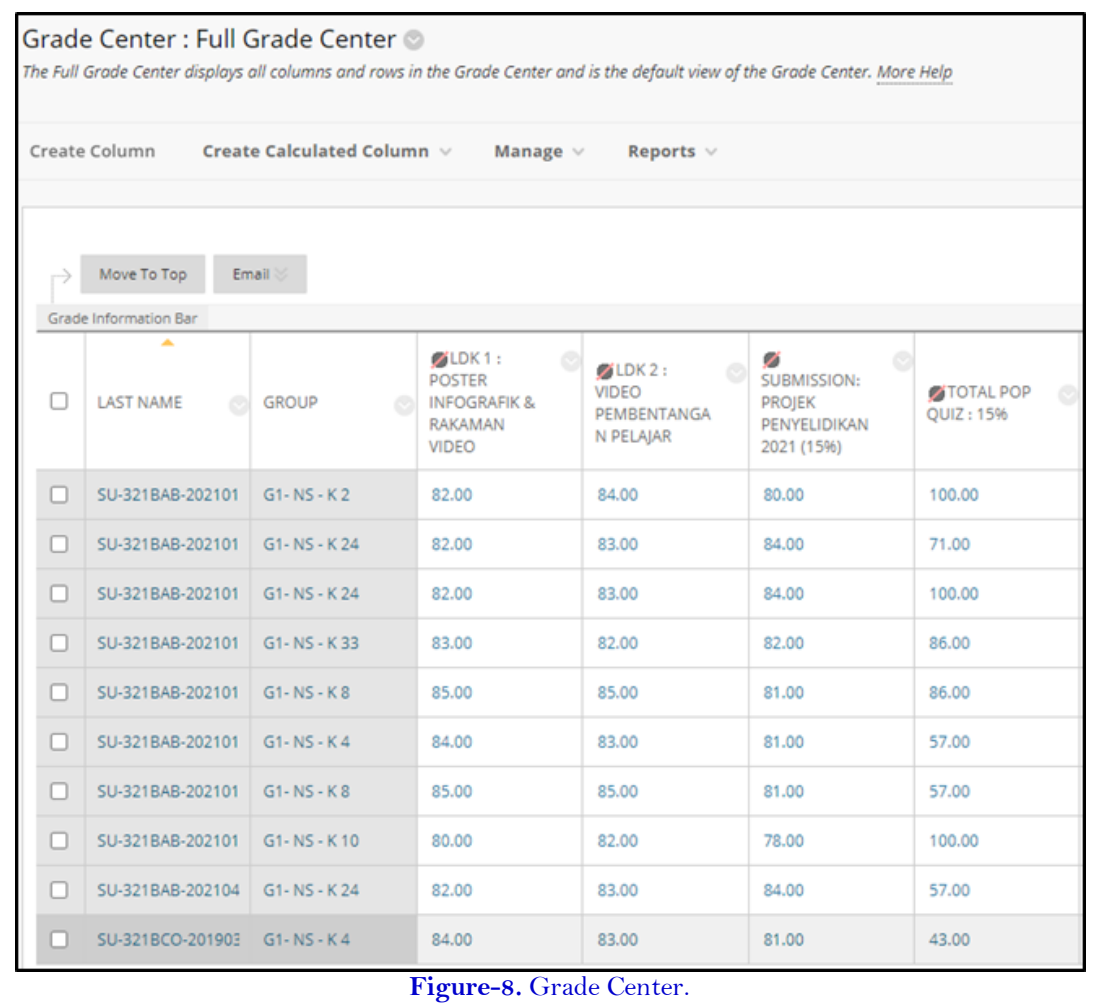

\begin{abstract}
"The advantages of using Grade Center are it allows me to monitor the results of online examinations, to check all activities that were submitted by students and to edit the scores or give comments manually through the Grade Center. For example, after all students have submitted their assignments through E-Learn, I will check all these assignments using Grade Center. Marking will be given based on the rubric provided for each assignment. I can also comment and give opinions on their assignments. Furthermore, it helps the lecturers to do basic calculations such as the average score or students' total scores. For instance, after all assignments have been scored, I can monitor the results for each assignment columns through Grade Center. This allows me to calculate total score of students as there is the column weight which will count all assignments that have been submitted by the students."
\end{abstract}

The above statement is an input provided by Lecturer 6 on the benefits of Grade Center which mainly focus on the monitoring of students' assessments and performance. As stated in Nkhoma, Nkhoma, Thomas, Tu, and Le (2019) in their research, "The formative assessments were connected to the grade-center which allowed the teachers to identify who has and has not been doing their preparation and hence the teachers would encourage the students to be more prepared and use the online materials". Following this, students are made known about the available content for the planned lesson, which subsequently can be followed up via synchronous interactions. Similarly, automated scores of the formative assessments can aid in identifying non-performing students in which a quantifiable facet such as percentages and average scores can be leveraged to modify online delivery. According to Gamage, Silva, and Gunawardhana (2020), in their research found that the formative assessment monitors student learning while providing ongoing feedback to staff and students. This form of assessment is largely for students' learning through understanding their strengths, weaknesses and improving their skills". Base on formative assessment lecturer can use to modify pedagogy in the structure of the online platform and gather information about student weaknesses to provide further support for their development through online assessment such as pop quizzes, midterm test or any type of individual assessment. 


\title{
3.7. Lockdown Browser
}

The Lockdown Browser features is usually used for Quizzes and Final Examinations. By using Lockdown Browser, students will not be able to copy, print, access other applications or visit other websites during the online examinations. Lockdown Browser also blocks hundreds of the latest and common digital cheating methods such as the usage of Virtual Machines, remote desktops, screen sharing, simple messaging, screen recording, key-press combination, the usage of timer or alarm apps, browser cache exploitation and many others. Therefore, the Lockdown Browser features can control and minimize the risk of cheating during online examinations. In addition, it also disables the right-click menu options, function keys, keyboard shortcuts and task switching. By using Lockdown Browser, students will not be able to copy from other students thus ensuring the transparency of the final examinations. Figure 9 shows the icons for Lockdown Browser used by the lecturers in General Studies Department:

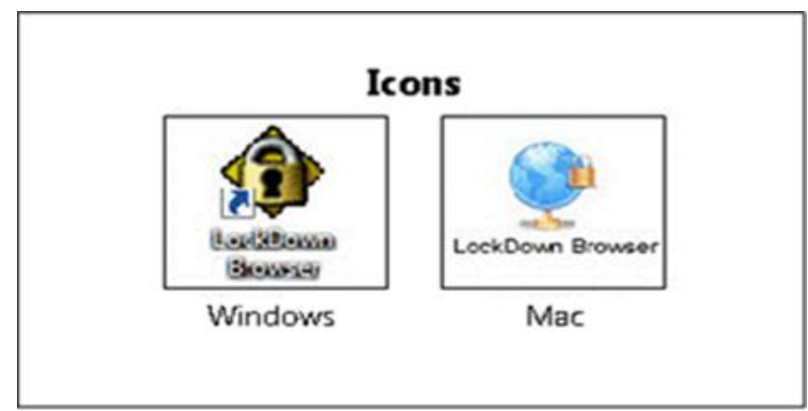

Figure-9. Lockdown Browser.

\begin{abstract}
"One benefit of using Lockdown Browser is that it can help the lecturers during grading process. Online examinations allow me to create exam questions through E-Learn which will then be linked to Lockdown Browser and the grading process will eventually by obtained automatically after students have finished answering the questions. This will never happen in traditional, manual examinations where lecturers have to use the OMR machine as all examination questions for general subjects are MCQs. Therefore, time can be saved by doing it using Lockdown Browser. Besides that, monitoring system in the E-Learn will prevent students from copying or cheating. Students must turn on their webcams and follow the standard operation procedures outlined in E-Learn in order to answer their examinations. Using E-Learn also save on paper usage. During online examinations, moderation is also carried out online, and this can further save paper usage to print the question for moderating. All questions can be kept in the Pool which is also the question banks in E-Learn. Furthermore, the filling system for examination questions can also be developed in a safer manner."
\end{abstract}

The input above was obtained from Lecturer 7 in which Lockdown browser is indicated to be able to facilitate the work of lecturers, especially for reviewing students' assessment marks and preventing students from committing any malpractice during the exam. Lockdown browser is an important feature in online learning applications to maintain the integrity of an online-based exam. In fact, it is also used by other universities in preparation for online exams such as the University of Sharjah, United Arab Emirates (Khalaf, El-Kishawi, Moufti, \& Al Kawas, 2020). To elaborate, medical students at this university also use Lockdown Browser during online exams because it is considered safe and most importantly is to prevent students from opening other websites while attempting online examinations. Karabaliev, Nedeva, Pehlivanova, and Minchev (2020) reiterated that Lockdown Browser is deemed as an essential mechanism to avert misconduct of online assessments. With Lockdown Browser, integrity of online assessments is unquestionable.

\section{CONCLUSION}

This study utilized reflective writing method to examine the experiences of GSD academics on the usage of ELearn as the teaching and learning modality whereby a qualitative-research design was leveraged to probe on the 
plethora of collective reflections and experiences. The findings obtained assert that the various features of E-Learn have tremendously helped GSD lecturers to adapt to the online teaching and learning during the pandemic. Some of the benefits of using E-Learn are the ability to relay information to the students, organize virtual classes, keep track of students' attendance and involvement in classes, upload videos, notes and slides, form group assignment and monitor groups workflow, design formative and summative assessments, final examinations and last but not least, supervise students' reports. It is deemed that E-Learn has suitable features that can be used as a platform or Learning Management System to support online teaching and learning. This is due to the fact that E-Learn is considered to be 'user-friendly', and there are two features in E-Learn that have greatly assisted the lecturers to engage with their students online, in particular, the 'E-Learn Announcements' and the 'BB Collaborate'. Nonetheless, based on the findings and limitations of the study, it is believed that the study must be further expanded in the future by involving the end users of E-Learn in which in-depth interview or survey can be administered. By doing so, more evidence and clearer effects of E-Learn as effective tools for online teaching and learning can be obtained.

Funding: This study received no specific financial support.

Competing Interests: The authors declare that they have no competing interests.

Acknowledgement: This is a collective research effort between the General Studies Department (GDS) academic staff and Associate Professor Dr Malissa Maria Mahmud from the Centre for English Language Studies (CELS), Sunway University. We would like to thank Associate Professor Dr Malissa Maria Mahmud for her mentorship and tremendous support, and also $\mathrm{Ms} \mathrm{Ng}$ Beng Lean for the encouragement provided for GSD academic staff to participate in the Seminar on Internal-External Quality Assurance (SieQA) 2021.

\section{REFERENCES}

Al Meajel, T. M., \& Sharadgah, T. A. (2018). Barriers to using the blackboard system in teaching and learning: Faculty perceptions. Technology, Knowledge and Learning, 23(2), 351-366. Available at: https://doi.org/10.1007/s10758-0179323-2.

Chan, C. K., Wong, H. Y., \& Luo, J. (2021). An exploratory study on assessing reflective writing from teachers' perspectives. Higher Education Research \& Development, 40(4), 706-720. Available at: https://doi.org/10.1080/07294360.2020.1773769.

Chen, J. C., Dobinson, T., \& Kent, S. (2020). Student's perspectives on the impact of blackboard collaborate on open university Australia (OUA) online learning. Journal of Educators Online, 17(1), n1.

Colomer, J., Serra, T., \& Canabate, D. (2020). Reflective learning in higher education: Actives methodologies for transformative practices. Sustainability, 12(9), 1-8. Available at: https://doi.org/10.3390/su12093827.

Elsamanoudy, A., Al Fayz, F., \& Hassanien, M. (2020). Adapting blackboard-collaborate ultra as an interactive online learning tool during the COVID-19 pandemic. Journal of Microscopy and Ultrastructure, 8(4), 213-215. Available at: https://doi.org/10.4103/jmau.jmau_26_20.

Ertmer, P. A. (2005). Teacher pedagogical beliefs: The final frontier in our quest for technology integration? Educational Technology Research and Development, 53(4), 25-39. Available at: https://doi.org/10.1007/bfo2504683.

Ertmer, P. A., \& Ottenbreit-Leftwich, A. T. (2010). Teacher technology change: How knowledge, confidence, beliefs, and culture intersect. Journal of research on Technology in Education, 42(3), 255-284. Available at: https://doi.org/10.1080/15391523.2010.10782551.

Fearnly, M. R., \& Amora, J. T. (2020). Learning management system adoption in higher education using the extended technology acceptance model. IAFOR Journal of Education: Technology in Education, 8(2), 89-106. Available at: https://doi.org/10.22492/ije.8.2.05.

Gamage, K. A., Silva, E. K. d., \& Gunawardhana, N. (2020). Online delivery and assessment during COVID-19: Safeguarding academic integrity. Education Sciences, 1O(11), 301. Available at: https://doi.org/10.3390/educsci10110301. 
Griffin, J., Lorenz, G. F., \& Mitchell, D. (2010). A study of outcomes-oriented student reflection during internship: The integrated, coordinated, and reflection based model of learning and experiential education. Journal of Cooperative Education \& Internships, 44(2), 42-50.

Hannah, Y. H., \& Jiahui, L. (2020). An expletory study on assessing reflective writing from teacher's perspective. Journal of The Higher Education Research and Development Society af Australasia, 26(2), 214-228.

Hatton, N., \& Smith, D. (1995). Reflection in teacher education: Towards definition and implementation. Teaching and Teacher Education, 11(1), 33-49. Available at: https://doi.org/10.1016/0742-051x(94)00012-u.

Hicks, D., Lee, J. K., Berson, M., Bolick, C., \& Diem, R. (2014). Guidelines for using technology to prepare social studies teachers. Contemporary Issues in Technology and Teacher Education, 14(4), 433-450.

Iffat Rahmatullah, S. (2021). Blackboard as online learning management system in Saudi context: Challenges and prospects. Paper presented at the Proceedings Of The AUBH E-Learning Conference 2021 : Innovative Learning \& Teaching - Lessons From COVID-19.

Jasper, M. A. (2005). Using reflective writing within research. Journal of Research in Nursing, 10(3), 247-260. Available at: https://doi.org/10.1177/174498710501000303.

Jennifer, M. A. (2004). A handbook of reflective and experiential learning" Theory and practice. Londres Y Nueva York: Routledge Falmer.

Karabaliev, M., Nedeva, V., Pehlivanova, T., \& Minchev. (2020). A reliable and secure online exams during the COVID-19 pandemic. Paper presented at the Proceedings of the 15th International Conference on Virtual Learning.

Khalaf, K., El-Kishawi, M., Moufti, M. A., \& Al Kawas, S. (2020). Introducing a comprehensive high-stake online exam to finalyear dental students during the COVID-19 pandemic and evaluation of its effectiveness. Medical Education Online, 25(1), 1-10. Available at: https://doi.org/10.1080/10872981.2020.1826861.

Koehler, M., \& Mishra, P. (2009). What is technological pedagogical content knowledge (TPACK)? Contemporary Issues in Technology and Teacher Education, 9(1), 60-70.

Mahmud, M. M., \& Bakar, M. S. A. (2021). E-Learn: An online platform for teaching and learning. International Journal of Academic Research in Progressive Education and Development, 9(4), 78-91. Available at: https://doi.org/10.6007/ijarped/v9-i4/8265.

Nieuwoudt, J. E. (2020). Investigating synchronous and asynchronous class attendance as predictors of academic success in online education. Australasian Journal of Educational Technology, 36(3), 15-25. Available at: https://doi.org/10.14742/ajet.5137.

Nkhoma, C., Nkhoma, M., Thomas, S., Tu, L. K., \& Le, N. Q. (2019). Transforming a first-year accounting course using a blended learning pathway. Issues in Informing Science छ Information Technology, 16, 319-342. Available at: https://doi.org/10.28945/4304.

Palansamy, Y. (2020). Higher education ministry: All university lectures to be online-only until end 2020, With A Few Exceptions" Malay Mail. Retrieved from: https://www.malaymail.com/news/malaysia/2020/05/27/highereducation-ministry-all-university-lectures-to-be-online-only-until-e/1869975.

Ryan, M., \& Ryan, M. (2013). Theorising a model for teaching and assessing reflective learning in higher education. Higher Education Research and Development, 32(2), 244-257. Available at: https://doi.org/10.1080/07294360.2012.661704.

Snellings, J. (2021). Asynchronous training for online teaching assistants. Instructional Design Capstones Collection, 72(2), 11-14.

Wang, X., Chen, W., Qiu, H., Eldurssi, A., Xie, F., \& Shen, J. (2020). A survey on the e-learning platforms used during COVID-19. Paper presented at the In 202011 th IEEE Annual Information Technology, Electronics And Mobile Communication Conference (IEMCON). 0808-0814.

Views and opinions expressed in this article are the views and opinions of the author(s), International Journal of Asian Social Science shall not be responsible or answerable for any loss, damage or liability etc. caused in relation to/arising out of the use of the content. 